\title{
Recent advances in chronotherapy for the management of asthma
}

\author{
This article was published in the following Dove Press journal: \\ ChronoPhysiology and Therapy \\ 26 November 2014 \\ Number of times this article has been viewed
}

\section{Hannah J Durrington' \\ Stuart N Farrow ${ }^{2,3}$ \\ David W Ray ${ }^{2}$}

'Institute of Inflammation and Repair, ${ }^{2}$ Institute of Human Development, Faculty of Medical and Human Sciences, University of Manchester, Manchester, UK; ${ }^{3}$ Respiratory Therapy Area, GlaxoSmithKline, Stevenage, UK

\begin{abstract}
Asthma is a common inflammatory disease of the airways, with a pronounced circadian variation in symptoms. A number of existing asthma treatments are "chronotherapies" designed to be delivered to coincide with the "morning dip" in lung function and corresponding worsening of symptoms. In the past decade, our knowledge of how circadian rhythms are regulated has increased immensely, and increasing evidence that the molecular clock plays a significant role in the immune system makes asthma an intriguing disease to study. The current trend toward once-daily dosing of asthma therapies reduces the need for careful timing of doses; however, patients are exposed to therapeutic levels of the drug and potential side effects for the entire day. Consequently, improved therapeutic benefit in asthma may be gained by understanding the molecular pathways that drive the predictable, diurnal worsening of symptoms. Furthermore, timing the delivery of therapy to coincide with pathway sensitivity may deliver maximum benefit. Defining the role of the molecular clock in these pathways could therefore lead to novel therapies and improved asthma control.
\end{abstract}

Keywords: anticholinergic, beta agonist, corticosteroids, $\mathrm{FEV}_{1}$, PEFR, theophylline

\section{Introduction}

\section{Asthma}

The number of people with asthma in the UK is among the highest in the world. More than 5 million people are affected. ${ }^{1}$ Asthma exacerbations lead to more than 60,000 hospital admissions with an annual expenditure of $£ 800$ million on pharmaceutical costs alone. In addition, it is estimated that asthma leads to a direct cost to the National Health Service (NHS) of $£ 1$ billion and an indirect cost to society, as a result of time off work, and loss of productivity of $£ 6$ billion. ${ }^{2}$

Asthma is a heterogeneous disease that results in recurrent, reversible bronchial obstruction. ${ }^{3}$ Symptoms of asthma include wheeze, cough, and breathlessness. Asthma is associated with airway hyperresponsiveness and chronic inflammation. Remarkably, there is still no consensus as to how to define asthma; however, in the last 10 years our understanding of the heterogeneity of the condition has increased immensely.

\section{Asthma pathophysiology - from phenotype to endotype} Initially, asthma was defined as a T-helper-type-2 (Th2)-cell-dependent, IgE-mediated allergic disease, triggered because of sensitization to aeroallergens. The pathology of asthma is characterized by mucus-cell hyperplasia and infiltration of inflammatory cells, predominantly CD4+ T-cells, eosinophils, and mast cells. ${ }^{4}$ Infiltrating T-cells express 
the Th2 cytokines interleukin 13 (IL-13), IL-4, and IL-5, ${ }^{5-7}$ which regulate many aspects of allergic inflammation. ${ }^{8}$ More recently, this T-cell-centric paradigm has been reinforced by the identification of Treg (regulatory T) cells with the capacity to control Th2 responses. ${ }^{9-11}$ A role for Th17 cells in nonatopic, obese asthma has been recognized. ${ }^{12,13}$ Interestingly, Th17 cell differentiation has been shown to be regulated by the circadian clock, specifically through the transcription factor REV-ERB $\alpha{ }^{14}$

Therapeutic agents developed to target Th2 inflammation have consistently worked in animal models; however, few have made the transition to humans. ${ }^{15}$ The significant phenotypic heterogeneity of asthma may be responsible for this and results from diverse genetic and environmental factors that underpin asthma pathogenesis. Recognition of the potential importance of specific phenotypes has led to recent studies seeking to define them. Clinicians have identified many different asthma phenotypes including those based on severity, liability (or not) of airflow obstruction, response to therapy, and age at onset. National and international guidelines are the biggest proponents of phenotyping $^{16}$ In a study of clinical phenotypes of adult asthma, clusters of patients were defined according to their relative expression of symptoms and eosinophilic inflammation. ${ }^{17}$ Patients with greater discordance between symptoms and inflammation were more difficult to treat and required treatment in specialized asthma centers. However, management aimed at reducing eosinophilic inflammation was better than usual treatment in both discordant groups (Figure 1).

Asthma phenotypes can be integrated with distinct pathophysiological mechanisms to describe asthma endotypes, which can then be treated accordingly. The future of asthma treatment will likely be guided by the asthma endotype. To this end, an analysis of molecular phenotyping in adult patients with mild, corticosteroid-naïve asthma examined expression profiling of bronchial biopsies and identified a Th2-high phenotype that is detectable in around $50 \%$ of adults with asthma and is marked by overexpression of IL-13-dependent genes (ie, POSTN, CLCA1, and SERPINB2). ${ }^{18}$ Patients classified as Th2-high were found to have higher amounts of tissue IL-13 and IL-5 messenger RNA (mRNA) and greater numbers of eosinophils and mast cells, and showed more atopy and thickening

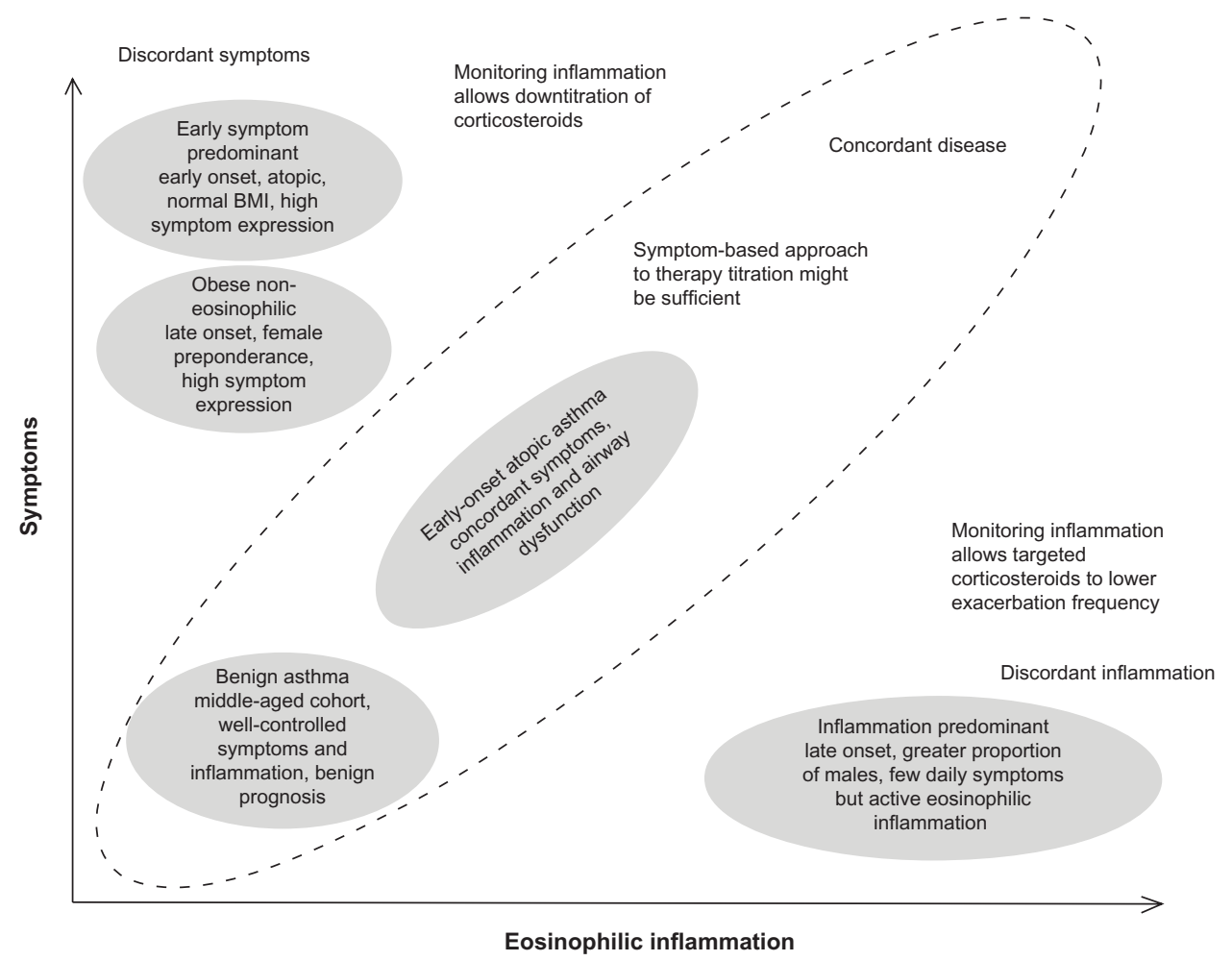

Figure I Clinical phenotypes of asthma.

Notes: A summary of phenotypes identified using cluster analysis. The clusters are plotted according to their relative expression of symptoms and inflammation because these are the two clinically pertinent and modifiable dimensions of the disease. Reprinted with permission of the American Thoracic Society. Copyright (C) 2008. American Thoracic Society. Haldar P, Pavord ID, Shaw DE, et al. 2008. Cluster analysis and clinical asthma phenotypes. Am J Respir Crit Care Med. I78:2 I8-224. ${ }^{17}$ Official Journal of the American Thoracic Society.

Abbreviation: BMI, body mass index. 
of the subepithelial basement membrane. These patients responded to inhaled corticosteroids (ICSs), whereas the Th2-low group did not. ${ }^{19}$ Lebrikizumab is a humanized monoclonal antibody to IL-13. Only asthmatics with high periostin levels respond to this treatment (periostin is a marker of IL-13 activity). ${ }^{20,21}$ Also, moderate-to-severe asthmatics with elevated circulating or sputum eosinophil levels who were poorly controlled on standard treatment were selected to receive dupilumab, a monoclonal antibody targeting both IL-4 and IL-13. ${ }^{22}$ In this population, treatment resulted in an $87 \%$ reduction in asthma exacerbations, indicating that careful selection of subject populations based on endotype can improve treatment efficacies that might be masked in a more heterogeneous population. The process of endotyping represents a move toward personalized medicine and has already enabled better clinical trial design. It may also lead to improved disease biomarkers and ultimately new therapeutic targets.

\section{Asthma and the circadian rhythm}

It is characteristic of asthma that symptoms worsen overnight, particularly in the early hours of the morning. Nocturnal symptoms in asthma are common and are an important indicator for escalation of treatment. An extensive body of research has demonstrated that nocturnal symptoms of cough and dyspnea are accompanied by circadian variations in airway inflammation and physiologic variables, including airflow limitation and airways hyperresponsiveness.

\section{Circadian variation in asthma symptoms}

Asthma is a disease with a strong circadian rhythm. Symptoms of asthma frequently show exacerbation in the early hours of the morning, at around $4 \mathrm{am}$. Sudden death in asthma also tends to occur at this time. ${ }^{23}$ In a survey of 7,729 patients with asthma, 74\% awoke at least once per week with asthma symptoms, 64\% reported nocturnal asthma symptoms at least three times per week, and approximately $40 \%$ of patients experienced symptoms nightly. ${ }^{24}$

\section{Circadian variation in lung physiology}

Physiological parameters of airway resistance, forced expiratory volume in 1 second $\left(\mathrm{FEV}_{1}\right)$, and peak expiratory flow rate (PEFR) are commonly measured in respiratory clinics and as outcome measures in drug trials. Both $\mathrm{FEV}_{1}$ and PEFR vary in a circadian manner in healthy individuals with a nadir at approximately $4 \mathrm{am}$. However, in asthma, the amplitude of the circadian rhythm of both $\mathrm{FEV}_{1}$ and PEFR is greatly magnified. ${ }^{25}$

\section{Circadian variation in airway inflammation}

Kraft et al performed bronchoscopy and transbronchial biopsy in subjects with nocturnal or nonnocturnal asthma at $4 \mathrm{pm}$ (the peak of lung function) and $4 \mathrm{am}$ (when airflow limitation was at its worst). In tissue from subjects with nocturnal asthma, there was a circadian variation in the number of alveolar eosinophils, with significantly more present at 4 am versus $4 \mathrm{pm}$. Increases in alveolar eosinophils in subjects with nocturnal asthma correlated with nocturnal decrease in $\mathrm{FEV}_{1}$. Circadian variation in tissue macrophages was also observed in alveolar tissue from subjects with nocturnal asthma. ${ }^{26}$ Although patients with nocturnal asthma typically meet criteria for moderate or severe persistent asthma, circadian changes in lung function can be seen in patients with milder asthma. In 2004, Kelly et al investigated circadian changes in airway inflammation in patients with mild atopic asthma (mean $\mathrm{FEV}_{1}$ of $93 \% \pm 4 \%$ of predicted value). In this patient population, bronchoalveolar lavage fluid contained increased numbers of macrophages, neutrophils, and CD4+ T lymphocytes at 4 am versus 4 pm. Additionally, the percentage of CD4+ $\mathrm{T}$ lymphocytes in the 4 am lavage fluid was inversely correlated with $4 \mathrm{am} \mathrm{FEV}_{1}{ }^{27}$

\section{How are circadian rhythms regulated?}

The suprachiasmatic nucleus of the mammalian brain serves as a central source of timing information to permit peripheral clocks to "track" day and night, as they lack light input. Both central and peripheral clocks use the same molecular machinery to "time" the day. Interlocking repressing and activating transcriptional and translational feedback loops culminate in the approximately 24-hour rhythmic expression and activity of a set of core clock genes in each organ. CLOCK and BMAL1 promote the transcription of period (PER1/2) and cryptochrome (CRY1/2) genes. As protein levels increase, PER and CRY associate and translocate into the nucleus directly, repressing CLOCK/BMAL1, thereby inhibiting their own transcription. Enzymatic degradation of PERIOD and CRYPTOCHROME proteins provides a delay mechanism prior to the onset of the next transcriptional cycle. The expression of positive factors, CLOCK and BMAL1, and negative factors, PER and CRY, are in antiphase to one another, providing circadian timing at the molecular level. Outputs from the molecular clock are generated through transcription or repression of target genes. BMAL1 is regulated by rhythmic interaction with REV-ERB $\alpha$. REV-ERB $\alpha$, a nuclear hormone receptor and core clock gene, is a critical regulator of inflammation and metabolism. REV-ERB $\alpha$ 
function can be regulated by small-molecule ligands and thus represents an exciting option for manipulation of the clock in disease states. ${ }^{28,29}$

\section{What is known about the peripheral lung clock?}

Work in our laboratory has demonstrated the presence of a local clock within the lung and specifically localized this clock to the Clara cell in the bronchial epithelium of mice. ${ }^{30}$ It has also been shown that disruption of circadian rhythms in mice, to mimic chronic jet lag or shift work, causes an alteration in lung mechanics and clock gene expression in the lung in a sexually dimorphic manner. ${ }^{31}$ Sukumaran et al conducted a genome-wide analysis of diurnal/nocturnal patterns in mRNA expression from lungs of rats kept in a tightly controlled 12:12 hour light-dark cycle. Cyclic oscillations in the expression of genes associated with extracellular matrix, cytoskeleton, cell cycle, and apoptosis were observed, suggesting that the repair and turnover of these components in lung are directly or indirectly clock controlled. Many of the growth factor ligands and receptors involved in the direct regulation of these processes and the maintenance of the homeostasis in lung also showed circadian-like oscillations in expression. In addition, many genes involved in processing of proteins, ranging from posttranslational modification to ubiquitin-mediated proteosomal degradation, also showed circadian oscillations in expression in lung. Genes coding for inflammatory molecules, including chemokine ligands (eg, Cxcl12) showed circadian-like oscillations in expression in lung, suggesting that the molecular clock can regulate the immune response in the organ. Furthermore, genes that are involved in the metabolism of xenobiotics showed circadianlike oscillations in expression in lung. ${ }^{32}$

\section{Immune clock}

Circadian variations in immune parameters such as lymphocyte proliferation, antigen presentation, and cytokine gene expression have been described. Recently, an association between the molecular circadian clock, immunity, and inflammation has been recognized. Importantly, the macrophage clockwork provides temporal gating of systemic responses to endotoxin, and, we have identified REV-ERB $\alpha$ as a key link between the clock and immune function. ${ }^{33}$ Furthermore, toll-like receptor 9 (TLR9) expression and function have been recently shown to be modulated by core circadian molecular clock components. In a vaccination model using TLR9 ligand as adjuvant, mice immunized at the time of enhanced TLR9 responsiveness presented weeks later with an improved adaptive immune response. In a TLR9-dependent mouse model of sepsis, disease severity was dependent on the timing of sepsis induction, coinciding with the daily changes in TLR9 expression and function. ${ }^{34}$ Therefore, the timing of an attack on the lung immune system by an allergen or virus might significantly affect the ability of the lung to mount an adequate immune response.

\section{What is the significance of circadian variation in asthma?}

The marked circadian variability in symptoms, airway physiology, and inflammation that occurs in asthma on a day-today basis suggests that the molecular clock plays an important role in the mechanisms that drive them. It is possible that, if the molecular clock is indeed responsible for "gating" the immune response within the lung, then chronic airway inflammation, typical of asthma, might be caused through disruption of essential clock regulation. This intriguing possibility merits further experimental and clinical study, and suggests that novel therapies targeting clock function may have important benefits in asthma management.

\section{Chronotherapy in asthma}

Chronotherapy may be accomplished by synchronizing drug concentrations to rhythms in disease activity, thus increasing efficacy as well as reducing adverse effects. The effectiveness of chronotherapy for asthma is most frequently determined by its effects on the morning dip in the lung function measurements

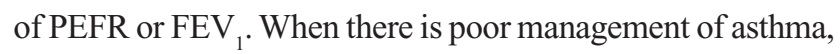
the morning PEFR is markedly lower than the evening PEFR. Most of the drugs that are currently used chronotherapeutically are administered once at night with the goal of preventing chronic airway inflammation or the onset of airflow limitation. Once-daily dosing also has the added benefit of improving patient adherence and promoting self-management of asthma. However, both PEFR and $\mathrm{FEV}_{1}$ reflect airway symptoms at a particular point in time. The inflammatory process that leads to this symptomology will have been triggered many hours earlier, with the transcription of pro-inflammatory genes and the subsequent stimulation of the immune system. Knowledge of the circadian rhythm of inflammatory biomarkers in the blood or sputum might allow us to narrow the chronotherapeutic window even further in the future.

\section{Current asthma treatment guidelines}

Current treatment guidelines do not reflect chronotherapy, phenotype, or endotype; rather they provide a linear treatment algorithm, based on asthma symptoms (Figure 2). ${ }^{35}$ 
ICSs, with or without long-acting beta agonists (LABAs), continue to be the mainstay of pharmacological treatment for mild-to-moderate asthma. Severe asthma is defined as asthma that requires treatment with high-dose ICSs plus a second controller and/or systemic corticosteroids to prevent it from becoming "uncontrolled" or that remains "uncontrolled" despite this therapy. ${ }^{36}$ Although the majority of asthma is effectively treated with existing medications, a substantial subset exists that remains difficult to treat.

\section{Current and emerging chronotherapies for asthma}

\section{$\beta_{2}$-adrenergic agonist medication}

$\beta_{2}$-agonists (BAs) primarily cause relaxation of airway smooth muscle, to increase airway caliber and relieve bronchoconstriction. However, BAs also have an anti-inflammatory action. ${ }^{37}$ Plasma epinephrine shows a circadian rhythm with the lowest level at 4 am and the highest level at 4 pm in both healthy subjects and patients with asthma. ${ }^{38}$ Both the BAs, procaterol and fenoterol, have been reported to strongly induce hPer1 mRNA expression in human bronchial epithelial cells in vitro. ${ }^{39} \mathrm{BAs}$ are predominantly inhaled and can be short-acting BA (SABA) with a duration of around 4 hours, or LABA effective for 12-24 hours. ${ }^{40}$ SABAs are prescribed as "reliever" medications for immediate relief from bronchoconstriction. The majority of LABAs are inhaled as aerosols (the advantage being delivery directly to the target area with fewer systemic side effects). LABAs can also be administered orally as tablets and as a transdermal preparation in the form of patches.

\section{LABA tablet formulation}

Terbutaline (Bricanyl Depot ${ }^{\circledR}$, AB Draco, Lund, Sweden) is a LABA tablet formulation that was one of the first to be assessed in chronotherapy trials. Daily doses were administered to asthmatics in synchrony with biological need defined in terms of the circadian rhythm of lung function (PEFR, $\mathrm{FEV}_{1}$ ). Five milligrams was administered in the morning ( $8 \mathrm{am}$ ) when the lung function was beginning to improve to its best level in the afternoon. Ten milligrams was administered

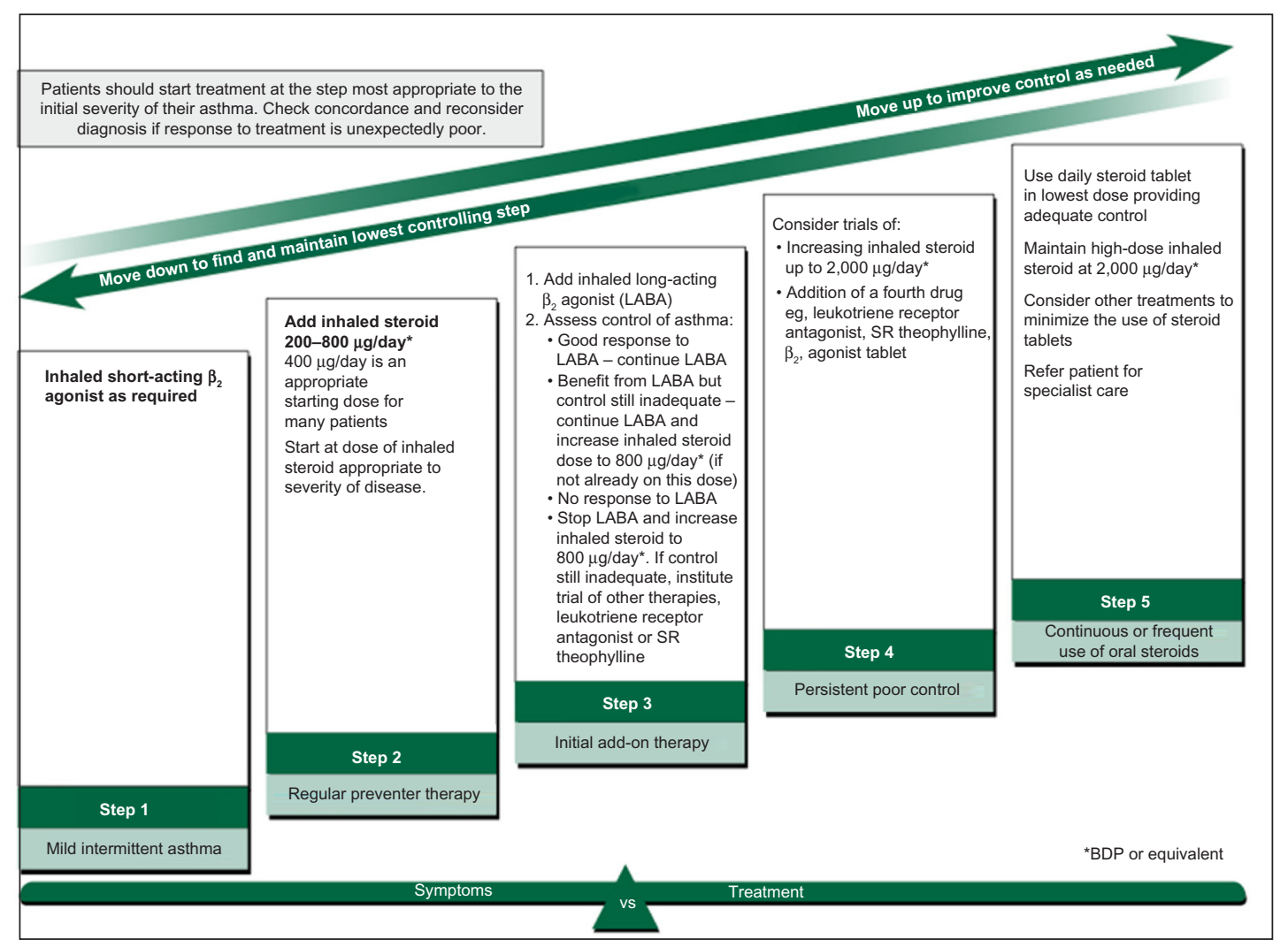

Figure 2 A summary of stepwise asthma management in adults.

Notes: Start treatment at the step most appropriate to initial severity. Achieve early control and maintain control by stepping up treatment as necessary and stepping down when control is good. Before initiating a new drug therapy, practitioners should check compliance with existing therapies and inhaler technique and eliminate trigger factors. Reproduced from British Guideline on the Management of Asthma, British Thoracic Society Scottish Intercollegiate Guidelines Network, Thorax 69 (Suppl I), ${ }^{35}$ Copyright (c) 2014, with permission from BMJ Publishing Group Ltd.

Abbreviations: BDP, beclomethasone dipropionate; LABA, long-acting $\beta$-agonists; SR, slow release. 
in the evening ( $8 \mathrm{pm})$ when lung function was beginning its decline to its worst level in the early hours of the morning. This chronotherapeutic strategy significantly increased the 24-hour mean PEFR and $\mathrm{FEV}_{1}$ and almost completely averted their characteristic nocturnal decline. ${ }^{41-43}$

Bambuterol (Bambec ${ }^{\circledR}$, Astra Draco, Lund, Sweden) is a prodrug of terbutaline and exerts a bronchodilator effect for 24 hours (Table 1). A chronotherapeutic trial of bambuterol investigated once-daily dosing with $20 \mathrm{mg}$ in the morning, versus the evening, versus placebo. Evening dosing resulted in a considerably higher morning $\mathrm{FEV}_{1}$ and PEFR. Overall, evening dosing was more advantageous because it improved $\mathrm{FEV}_{1}$ throughout the 24 hours to a greater extent than morning dosing (although nonstatistically significant due to small sample size). Neither of the bambuterol treatment regimens was associated with any cardiovascular or nervous system adverse effects.

\section{LABA inhaler medication}

Formoterol (Novartis, Basel, Switzerland) and salmeterol (GlaxoSmithKline plc, London, UK, and USA) are aerosol LABA medications, with few adverse effects. Both

Table I Chronopharmaceutical technologies for the treatment of asthma

\begin{tabular}{|c|c|c|}
\hline Technology & Chronopharmaceutical technology & Chronotherapeutic studies \\
\hline $\begin{array}{l}\text { Hokunalin }^{\circledR} \text { Tape } \\
\text { (Abbott Japan Co, Ltd, Osaka, Japan) }\end{array}$ & $\begin{array}{l}\text { Transdermal chronodelivery system for Tulobuterol, } \\
\text { a LABA. Maintains an effective drug concentration } \\
\text { over } 24 \text { hours. }\end{array}$ & $\begin{array}{l}\text { Application of patch between } 7 \mathrm{pm} \\
\text { and } 9 \mathrm{pm} \text { for } 6 \text { consecutive days } \\
\text { leads to markedly improved morning } \\
\text { PEFR, compliance, and allergic airway } \\
\text { inflammation. }{ }^{85-87}\end{array}$ \\
\hline $\begin{array}{l}\text { Proventil Repetabs }{ }^{\circledR} \text { (Bayer-Schering, } \\
\text { Berlin, Germany) }\end{array}$ & $\begin{array}{l}\text { Pulse-release LABA tablet design. An outer coat } \\
\text { of } 2 \mathrm{mg} \text { albuterol surrounds an inner subcoat. } \\
\text { A third "barrier coat" is insoluble in the acid of the } \\
\text { stomach, but soluble in the alkaline small intestine, } \\
\text { thus exposing the core of the tablet containing } \\
\text { an additional } 2 \mathrm{mg} \text { albuterol. Half the dose is released }\end{array}$ & $\begin{array}{l}\text { Proventil Repetabs }{ }^{\circledR} \text { given twice a day } \\
(4 \mathrm{mg} \text { in the morning and a larger dose } \\
\text { at nighttime) demonstrated a significant } \\
\text { reduction in nocturnal PEFR dip and } \\
\text { nighttime symptoms when compared } \\
\text { to placebo. }{ }^{89}\end{array}$ \\
\hline
\end{tabular}

Bambuterol (Bambec ${ }^{\circledR}$, Astra Draco, Sweden)

Sustained-release albuterol (Volmax ${ }^{\circledR}$; GlaxoSmithKline plc, London, UK; Muro, USA)

Dutimelan $^{\circledR}$ (Sanofi, Paris, France)

Contin $^{\circledast}$

Pastillation of doxofylline within the first 6 hours, and the rest is released during the next 6 hours. $^{88}$

Once-daily prodrug of terbutaline; lasts

for 24 hours. After absorption, bambuterol

is protected from hydrolysis by an esterase-inhibiting function built into the prodrug molecule. Bambuterol is slowly metabolized in the liver, and terbutaline is generated in a controlled fashion during 24 hours. ${ }^{90}$ Albuterol tablet with 12/24 hour dosing intervals. ${ }^{91,92}$

Contains a rate-controlling semipermeable

membrane, and a core of albuterol and osmotic agent. An osmotic gradient draws water into the tablet, albuterol dissolves, and it is released from the polymeric coated tablets through a laser-drilled hole on one side of the tablet (OROS ${ }^{\mathrm{TM}}$ technology).

A different mix and concentration of synthetic glucocorticoids. The stronger 8 am dose consists of $7 \mathrm{mg}$ prednisolone acetate and $4 \mathrm{mg}$ prednisolone alcohol, while the $3 \mathrm{pm}$ dose consists of $3 \mathrm{mg}$ prednisolone alcohol and $15 \mathrm{mg}$ cortisone acetate. Sustained release Uniphyl ${ }^{\circledast /} /$ Uniphyllin $^{\circledR}$ tablet. Complexes are formed between a cellulose polymer and a nonpolar solid aliphatic alcohol. Used for controlled-release formulations since it has a uniform porosity. ${ }^{94}$

A novel "pastillation" process applied to doxofylline, a new bronchodilator, derived from theophylline. Delivers an immediate "pulse" of drug after a delay of about 5 hours.
In a I-month course of treatment, Dutimelan significantly improved airway caliber without causing adrenocortical suppression. ${ }^{93}$

Evening dosing means maximal drug is released at the time of minimal PEFR. ${ }^{95}$ 
medications have duration of action of about 12 hours, although formoterol may have a more rapid onset of affect. ${ }^{44,45}$ Formoterol and salmeterol are similar in chemical structure, except that salmeterol possesses an elongated side chain that binds the molecule firmly to the $\beta_{2}$-adrenoceptor, allowing it to repeatedly excite the receptor. ${ }^{46}$ Overall, the results of many large-scale studies demonstrate that twicedaily, 12-hour interval dosing of $50 \mu \mathrm{g}$ salmeterol, compared to the dosing of 180-200 $\mu \mathrm{g}$ albuterol four times daily, results in better control of overnight and morning PEFR and $\mathrm{FEV}_{1}$, reduces daytime and nighttime asthma frequency, lowers patient dependence on BA aerosol rescue medication, and improves nighttime sleep. ${ }^{47-53}$ However, the chronotherapy of LABA has not been extensively investigated, and it would be interesting to investigate the chronobiological effects of nighttime versus morning once-daily dosing with these agents.

Indacaterol and vilanterol are ultra-LABAs that act for 24 hours. Data so far suggest that a single morning dose of indacaterol significantly improves the 24-hour trough $\mathrm{FEV}_{1}$, compared with twice-daily formoterol and placebo. ${ }^{54}$ A study to investigate the effect of time of day of dosing (morning or evening) on lung function following administration of fluticasone furoate/vilanterol 100/25 $\mu \mathrm{g}$, showed no significant differences between morning or evening dosing in patients with persistent asthma. ${ }^{55}$ This suggests that the timing of dosing with ultra-LABAs is not important. However, any circadian effects of these long-acting drugs may well be masked.

\section{Anticholinergic agents}

Cholinergic tone from vagal nerves in the parasympathetic system increases at night and may cause bronchoconstriction and mucus secretion. ${ }^{56,57}$ It has been suggested that the vagal nerve is one of the dominant pathways for conveying circadian signals from the suprachiasmatic nucleus master clock to the peripheral clock in the respiratory tract. ${ }^{58}$ Inhaled muscarinic antagonists are classified according to their duration of action. Short-acting muscarinic antagonists (SAMAs) include ipratropium bromide and long-acting muscarinic antagonists (LAMAs) include tiotropium, aclidinium, and glycopyrronium. However, inhaled anticholinergic agents demonstrate inconsistent results in patients with nocturnal asthma. ${ }^{59,60}$ It has been postulated that the failure of traditional equal-interval, equal-dose regimens to impact airway caliber and protect against asthma overnight could be due to less than adequate dosing of this class of medications late in the day and/or at bedtime. ${ }^{57}$ In fact, several studies have shown that, if a sufficiently large dose of early generation anticholinergic medication was administered late at night or very early in the morning, there was attenuation of the nocturnal decline in peak expiratory flow (PEF) in nocturnal asthmatics. ${ }^{59-61}$

Of the LAMAs, tiotropium is the most widely studied in asthma. Tiotropium is an anticholinergic medication that dissociates slowly from the muscarinic M3 receptor, found on bronchial smooth muscle. It therefore has a prolonged duration of action of more than 24 hours. It can be inhaled as a dry powder (Handihaler ${ }^{\circledR}$, Boehringer Ingelheim, Ingleheim am Rhine, Germany) or as a fine particle mist (Respimat ${ }^{\circledR}$, Boehringer Ingelheim, Ingleheim am Rhine, Germany). Tiotropium has been shown to be an effective asthma treatment in patients inadequately controlled on ICSs alone or in combination with a LABA. ${ }^{62}$ Tiotropium showed no significant differences in effect on airway caliber when administered once daily in the morning versus evening. ${ }^{63}$ However, the long duration of action of this high-affinity medication may mask possible circadian time-dependent effects.

\section{Systemic corticosteroids}

Oral steroids are used as a short-term "burst" at step 5 of the British Thoracic Society (BTS)/SIGN (Scottish Intercollegiate Guidelines Network) guidelines to control acute deterioration in asthma control. ${ }^{35}$ However, many patients with severe asthma are controlled on long-term "maintenance" oral corticosteroids and will be affected by the many adverse side effects.

Chronotherapeutic studies investigating the use of synthetic steroids must take into account the pronounced endogenous circadian variation in cortisol levels. Cortisol is highest in the morning and lowest during night. In a study to investigate how the time of administration of synthetic steroid affects the endogenous circadian rhythm of cortisol secretion, administration of synthetic methylprednisolone by infusion between 8 am and 4 pm resulted in no adrenal suppression; however, infusion between 12 am and 4 am resulted in very severe adrenocortical suppression. Infusion during $4 \mathrm{pm}$ and $8 \mathrm{pm}$ and also between 4 am and 8 am resulted in moderate adrenocortical suppression. ${ }^{64}$

Beam et al conducted a double-blinded, placebocontrolled, crossover protocol to study the effect of either $50 \mathrm{mg}$ prednisolone or placebo given at $8 \mathrm{am}, 3 \mathrm{pm}$, or $8 \mathrm{pm}$ on $\mathrm{FEV}_{1}$ in patients with uncontrolled nocturnal asthma. Surprisingly, the $50 \mathrm{mg}$ prednisolone dose attenuated the nocturnal decline in $\mathrm{FEV}_{1}$ only when ingested at $3 \mathrm{pm}$. 
The ingestion of $50 \mathrm{mg}$ prednisolone at 8 am or $8 \mathrm{pm}$ was ineffective. ${ }^{65}$ These results are consistent with other studies, ${ }^{66}$ suggesting that synthetic corticosteroids administered at $3 \mathrm{pm}$ are more effective in nocturnal asthma and cause less disruption to endogenous circadian cortisol rhythm. In future, more lengthy clinical trials are required in this area.

\section{Inhaled corticosteroids}

ICSs are the mainstay of asthma treatment and are used at step 2 in the BTS asthma guidelines ${ }^{35}$ (Figure 2). ICSs are very effective in controlling asthma symptoms in asthmatic patients of all ages and severity. ${ }^{67,68}$ The advantage of inhaled therapy is that corticosteroid is delivered specifically to the target area. However, this is dependent on the ability of the subject to correctly use the inhaler device; deposition of the ICS in the oropharynx will lead to increased systemic absorption and the development of associated side effects. ICSs inhibit inflammatory cytokines and reduce airway hyperresponsiveness. ICSs reduce mast cells, $\mathrm{T}$ lymphocytes, and eosinophils in the bronchial epithelium and submucosa. ${ }^{69,70}$

Several studies have investigated the chronotherapy of ICSs. In one study, triamcinolone acetate aerosol when given to asthmatics at $3 \mathrm{pm}(800 \mu \mathrm{g})$ was found to be at least equivalent compared to the conventional four-times-a-day (200 $\mu \mathrm{g})$ treatment schedule. ${ }^{71}$ In a second study, Pincus et al compared four-times-a-day triamcinolone acetate ( $800 \mu \mathrm{g} /$ day) with single 8 am or $5.30 \mathrm{pm}$ once-daily dosing regimens in moderately severe nocturnal asthmatics. Both the four-times-a-day and the $5.30 \mathrm{pm}$ dosing regimens improved the morning and evening PEF in a comparable manner, but not the single 8 am dose. Furthermore, there were no differences in systemic effects, including adreno-cortical suppression, between treatment groups. ${ }^{72}$ These results are consistent with chronotherapeutic studies investigating oral corticosteroids.

Ciclesonide (Alvesco ${ }^{\circledR}$, Teijin Pharma Ltd, Tokyo, Japan) is a novel ICS administered once daily at night by a metered-dose inhaler. Dosing with ciclesonide once daily in the morning or evening significantly improves PEF and $\mathrm{FEV}_{1}$ without causing adrenocortical suppression; however, the evening dosing regimen best improved the morning PEF. ${ }^{73,74}$ Once-daily ciclesonide (160 $\mu \mathrm{g}$ dose) has been shown to be as effective as twice-daily ( $88 \mu \mathrm{g}$ dose) fluticasone in improving airway caliber, controlling asthma symptoms, and reducing reliance on rescue medication. ${ }^{75}$

\section{Theophyllines}

Theophyllines, although relatively weak bronchodilators, possess significant anti-inflammatory effects. In asthmatic patients, theophylline inhibits the late response to allergen, increases CD8+ cells in peripheral blood, and decreases T lymphocytes in the airways. ${ }^{76,77}$ Sustained release theophyllines can be added at step 3 of the BTS/SIGN guidelines ${ }^{35}$ (Figure 2) if there has been no response to LABA.

Both the kinetics and the adverse effects of theophyllines vary depending on whether the drug is taken in the morning or evening. The chronotherapy of theophylline entails the purposeful delivery of medication in unequal amounts during 24 hours so that an elevated concentration is achieved during the nighttime, when the risk of asthma is greatest, and a reduced concentration is achieved during the daytime, when the risk of asthma is lowest. Euphyllin ${ }^{\circledR}$ (Byk Gulden, Konstanz, Germany) was developed in the 1980s as a sustained release, asymmetric morning-evening dosed theophylline preparation. ${ }^{78}$ However, the asymmetric dosing schedule reduces patient adherence, and so once-daily preparations were developed. Euphylong ${ }^{\circledR}$ (Byk Gulden) and Uniphyl $^{\circledR}$ (Purdue Frederick, Stamford, CT, USA)/Uniphyllin ${ }^{\circledR}$ (Mundipharma, Limburg, Germany) are dosed at night with the intention of achieving peak concentration overnight/early morning when the drop in PEF is the greatest. When oncedaily dosing in the evening (chronotherapy) is compared to twice-daily and round-the-clock dosing in asthmatic patients with a nocturnal dip on PEF, once-daily evening administration was more effective for increasing the serum theophylline concentration at the time when lung function was worse, and this regimen improved both symptoms and PEF. ${ }^{79}$

\section{Leukotriene receptor antagonists}

Leukotrienes are formed by the degradation of arachidonic acid by $5^{\prime}$-lipoxygenase. They are pro-inflammatory and bronchoconstrictor mediators. The leukotriene receptor antagonists (montelukast, pranlukast, and zafirlukast) and the 5-lipoxygenase inhibitor zileuton are a new class of anti-inflammatory drugs that reduce leukocyte traffic and modulate airway inflammation and bronchial hyperresponsiveness. ${ }^{80-82}$ Leukotriene receptor antagonists are used at step 3 of the BTS/SIGN guidelines ${ }^{35}$ (Figure 2) as add-on therapy. Montelukast is recommended for ingestion once daily in the evening; however, it is not marketed as a chronotherapy. A double-blind study showed that montelukast better improved $\mathrm{FEV}_{1}$ when dosed in the evening than morning, ${ }^{82}$ and a second study confirmed this and also showed that even once-daily, low-dose (10 mg) 
evening montelukast dosing improves asthma. ${ }^{83}$ Zileuton was initially formulated to be taken four times a day; however, an extended-release tablet is now available with twice-daily dosing. Zileuton therapy is monitored because of the risk of hepatic toxicity. Future chronotherapy trials for Zileuton could potentially provide a therapeutic window, by changing the delivery time to coincide with a key pathway, which would negate the need for steady state levels of Zileuton throughout the day, and may reduce the risk of side effects.

\section{Chronopharmaceutical technologies for the treatment of asthma}

Novel technologies have been developed to allow medications to be taken at a convenient time of day (to help improve compliance) but allow the release of drug to be delayed to coincide with the "morning dip" in PEFR (Table 1).

\section{Conclusion - the future of chronotherapy for asthma}

Elucidating the molecular pathways that precede the diurnal worsening of symptoms may provide a major advance in treatment options for patients with asthma. Additionally, defining the role of the molecular clock in these pathways may provide a novel therapeutic target. Topically delivered, clock-acting compounds might allow selective manipulation of the pulmonary clock. Furthermore, targeting a welldefined circadian molecular pathway at a predictable time point, when the pathway is upregulated, will result in more efficacious therapies, active for shorter periods of time, with fewer side effects. Determining circadian molecular pathways underpinning asthma biology may also provide the rationale for clinical trials, using existing therapies at different time points and at lower doses.

\section{Acknowledgment}

HJD is supported by a Senior Career Development Award from Asthma UK.

\section{Disclosure}

The authors report no conflicts of interest in this work.

\section{References}

1. Royal College of Physicians. Why asthma still kills: the National Review of Asthma Deaths (NRAD) Confidential Enquiry report. London, UK: RCP, 2014.

2. Asthma UK. 2014. Available from: http://www.asthma.org.uk.

3. Martinez FD, Vercelli D. Asthma. Lancet. 2013;382:1360-1372.

4. Hogg JC. Pathology of asthma. J Allergy Clin Immunol. 1993;92: $1-5$.
5. Bentley AM, Maestrelli P, Saetta M, et al. Activated T-lymphocytes and eosinophils in the bronchial mucosa in isocyanate-induced asthma. J Allergy Clin Immunol. 1992;89:821-829.

6. Bentley AM, Meng Q, Robinson DS, Hamid Q, Kay AB, Durham SR. Increases in activated $\mathrm{T}$ lymphocytes, eosinophils, and cytokine mRNA expression for interleukin-5 and granulocyte/macrophage colonystimulating factor in bronchial biopsies after allergen inhalation challenge in atopic asthmatics. Am J Respir Cell Mol Biol. 1993;8:35-42.

7. Bradley BL, Azzawi M, Jacobson M, et al. Eosinophils, T-lymphocytes, mast cells, neutrophils, and macrophages in bronchial biopsy specimens from atopic subjects with asthma: comparison with biopsy specimens from atopic subjects without asthma and normal control subjects and relationship to bronchial hyperresponsiveness. J Allergy Clin Immunol. 1991;88:661-674.

8. Cohn L, Elias JA, Chupp GL. Asthma: mechanisms of disease persistence and progression. Annu Rev Immunol. 2004;22:789-815.

9. van Oosterhout AJ, Bloksma N. Regulatory T-lymphocytes in asthma. Eur Respir J. 2995;26:918-932.

10. Umetsu DT, Akbari O, Dekruyff RH. Regulatory T cells control the development of allergic disease and asthma. J Allergy Clin Immunol. 2003;112:480-487.

11. Larche M. Regulatory T cells in allergy and asthma. Chest. 2007;132: 1007-1014.

12. McKinley L, Alcorn JF, Peterson A, et al. TH17 cells mediate steroidresistant airway inflammation and airway hyperresponsiveness in mice. J Immunol. 2008;181:4089-4097.

13. Kim HY, Lee HJ, Chang YJ, et al. Interleukin-17-producing innate lymphoid cells and the NLRP3 inflammasome facilitate obesity-associated airway hyperreactivity. Nat Med. 2014;20:54-61.

14. Yu X, Rollins D, Ruhn KA, et al. $\mathrm{T}_{\mathrm{H}} 17$ Cell differentiation is regulated by the circadian clock. Science. 2013;342:727-730.

15. Holgate ST. Pathophysiology of asthma: what has our current understanding taught us about new therapeutic approaches? J Allergy Clin Immunol. 2011;128:495-505.

16. National Asthma Education and Prevention Program. Expert Panel Report 2: Guidelines for the Diagnosis and Management of Asthma, Publication No 97-4051. Bethesda, MD: US Department of Health and Human Services; 1997.

17. Haldar P, Pavord ID, Shaw DE, et al. Cluster analysis and clinical asthma phenotypes. Am J Respir Crit Care Med. 2008;178:218-224.

18. Woodruff PG, Modrek B, Choy DF, et al. T-helper type 2-driven inflammation defines major subphenotypes of asthma. Am J Respir Crit Care Med. 2009;180:388-395.

19. Dougherty RH, Sidhu SS, Raman K, et al. Accumulation of intraepithelial mast cells with a unique protease phenotype in $\mathrm{T}(\mathrm{H}) 2$-high asthma. J Allergy Clin Immunol. 2010;125:1046-1053.

20. Thomson NC, Patel M, Smith AD. Lebrikizumab in the personalized management of asthma. Biologics. 2012;6:329-335.

21. Corren J, Lemanske RF, Hanania NA, et al. Lebrikizumab treatment in adults with asthma. $N$ Engl J Med. 2011;365:1088-1098.

22. Wenzel S, Ford L, Pearlman D, et al. Dupilumab in persistent asthma with elevated eosinophil levels. $N$ Engl J Med. 2013;368:2455-2466.

23. Cochrane GM, Clark TJH. A survey of asthma mortality in patients between ages 35 and 64 in Greater London Hospitals in 1971. Thorax. 1975;30:300-305.

24. Turner-Warwick M. Epidemiology of nocturnal asthma. Am J Med. 1988;85:6-8.

25. Sutherland ER. Nocturnal asthma. J Allergy Clin Immunol. 2005;6: 1179-1186.

26. Kraft M, Martin RJ, Wilson S, Djukanovic R, Holgate ST. Lymphocyte and eosinophil influx into alveolar tissue in nocturnal asthma. Am J Respir Crit Care Med. 1999;159:228-234.

27. Kelly EA, Houtman JJ, Jarjour NN. Inflammatory changes associated with circadian variation in pulmonary function in subjects with mild asthma. Clin Exp Allergy. 2004;34:227-233.

28. Trebble PJ, Woolven JM, Saunders KA, et al. A ligand-specific kinetic switch regulates glucocorticoid receptor trafficking and function. J Cell Sci. 2013;15:3159-3169. 
29. Trump RP, Bresciani S, Cooper AW, et al. Optimized chemical probes for REV-ERB $\alpha$. J Med Chem. 2013;56(11):4729-4737.

30. Gibbs JE, Beesley S, Plumb L, et al. Circadian timing in the lung; a specific role of bronchiolar epithelial cells. Endocrinology. 2009;150: 268-276.

31. Hadden H, Soldin SJ, Massaro D. Circadian disruption alters mouse lung clock gene expression and lung mechanics. J Appl Physiol. 2012;113:385-392.

32. Sukumaran S, Jusko WJ, DuBois DC, Almon RR. Light-dark oscillations in the lung transcriptome: implications for lung homeostasis, repair, metabolism, disease and drug action. J Appl Physiol. 2011;110: 1732-1747.

33. Gibbs JE, Blaikley J, Beesley S, et al. The nuclear receptor REV-ERB $\alpha$ mediates circadian regulation of innate immunity through selective regulation of inflammatory cytokines. Proc Natl Acad Sci U S A. 2012;109:582-587.

34. Silver AC, Arjona A, Walker WE, Fikrig E. The circadian clock controls toll-like receptor 9-mediated innate and adaptive immunity. Immunity. 2012;36:251-261.

35. British Thoracic Society and Scottish Intercollegiate Guidelines Network. British Guideline on the Management of Asthma. Thorax. 2014:69 (Suppl 1).

36. Chung KF, Wenzel SE, Brozek JL, et al. International ERS/ATS guidelines on definition, evaluation and treatment of severe asthma. Eur Respir J. 2014;43:343-373.

37. Maneechotesuwan K, Essilfie-Quaye S, Meah S, et al. Formoterol attenuates neutrophilic airway inflammation in asthma. Chest. 2005;128:1936-1942.

38. Barnes P, FitzGerald G, Brown M, Dollery C. Nocturnal asthma and changes in circulating epinephrine, histamine and cortisol. $N$ Engl $J$ Med. 1980;303:263-267.

39. Takata M, Burioka N, Ohdo S, et al. $\beta_{2}$-adrenoceptor agonists induce the mammalian clock gene hPer1 mRNA in cultured human bronchial epithelium cells in vitro. Chronobiol Int. 2005;22:777-783.

40. Twentyman OP, Finnerty JP, Harris A, Palmer J, Holgate ST. Protection against allergen-induced asthma by salmeterol. Lancet. 1990;336:1338-1342.

41. Postma DS, Koëter GH, Keyzer JJ, Meurs H. Influence of slow-release terbutaline on the circadian variation of catecholamines, histamine, and lung function in nonallergic patients with partly reversible airflow obstruction. J Allergy Clin Immunol. 1986;77:471-477.

42. Koëter GH, Postma DS, Keyzer JJ, Meurs H. Effect of oral slowrelease terbutaline on early morning dyspnoea. Eur J Clin Pharmacol. 1985;28:159-162.

43. Dahl R, Harving H, Säwedal L, Anehus S. Terbutaline sustained-release tablets in nocturnal asthma - a placebo-controlled comparison between a high and a low evening dose. Br J Dis Chest. 1988;82:237-241.

44. Arvidsson P, Larsson S, Löfdahl CG, Melander B, Svedmyr N, Wåhlander L. Inhaled formoterol during one year in asthma: a comparison with salbutamol. Eur Respir J. 1991;4:1168-1173.

45. Kesten S, Chapman KR, Broder I, et al. Sustained improvement in asthma with long-term use of formoterol fumarate. Ann Allergy. 1992;69:415-420

46. Ball DI, Brittain RT, Coleman RA, et al. Salmeterol, a novel, long-acting beta 2-adrenoceptor agonist: characterization of pharmacological activity in vitro and in vivo. Br J Pharmacol. 1991;104:665-671.

47. Brambilla C, Chastang C, Georges D, Bertin L. Salmeterol compared with slow-release terbutaline in nocturnal asthma. Allergy. 1994;49: 421-426.

48. Britton MG, Earnshaw JS, Palmer JBD. A twelve month comparison of salmeterol and salbutamol in asthmatic patients. Eur Respir J. 1992;5:1062-1067.

49. D’Alonzo GE, Nathan RA, Henochowicz S, Morris RJ, Rathner P, Rennard SI. Salmeterol xinafoate as maintenance therapy compared with albuterol in patients with asthma. JAMA. 1994;271:1412-1416.

50. Fitzpatrick MF, Mackay T, Driver H, Douglas NJ. Salmeterol in nocturnal asthma: a double-blind, placebo controlled trial of a long acting inhaled $\beta 2$ agonist. Br Med J. 1990;301:1365-1368.
51. Lundback B, Rawlinson DW, Palmer JBD. Twelve month comparison of salmeterol and salbutamol as dry powder formulations in asthmatic patients. Thorax. 1993;48:148-153.

52. Pearlman DS, Chervinsky P, LaForce C, et al. A comparison of salmeterol with albuterol in the treatment of mild-to-moderate asthma. N Engl J Med. 1992;327:1420-1425.

53. Ullman J, Hedner J, Svedmyr N. Inhaled salmeterol and salbutamol in asthmatic patients. Am Rev Respir Dis. 1990;142:571-575.

54. LaForce C, Korenblat P, Osborne P, Dong F, Higgins M. 24-hour bronchodilator efficacy of single doses of indacaterol in patients with persistent asthma: comparison with placebo and formoterol. Curr Med Res Opin. 2009;25(10):2353-2359.

55. Kempsford RD, Oliver A, Bal J, Tombs L, Quinn D. The efficacy of once-daily fluticasone furoate/vilanterol in asthma is comparable with morning or evening dosing. Respir Med. 2013;107(12):1873-1880.

56. The Global Initiative for Asthma (GINA) Report, Global Strategy for Asthma Management and Prevention, Evidence-Based Guidelines for Asthma Management and Prevention. Updated Dec 2008.

57. Smolensky MH, Lemmer AE, Reinberg AE. Chronobiology and chronotherapy of allergic rhinitis and bronchial asthma. Adv Drug Deliv Rev. 2007;59:852-882.

58. Bando H, Nishio T, van der Horst GT, Masubuchi S, Hisa Y, Okamura H. Vagal regulation of respiratory clocks in mice. J Neurosci. 2007;27:4359-4365.

59. Coe CI, Barnes PJ. Reduction of nocturnal asthma by an inhaled anticholinergic drug. Chest. 1986;90:485-488.

60. Morrison JFJ, Pearson SB, Dean HG. Parasympathetic nervous system in nocturnal asthma. Br Med J. 1988;296:1427-1429.

61. Gaultier C, Reinberg A, Girard F. Circadian changes in lung resistance and dynamic compliance in healthy and asthmatic children. Effects of two bronchodilators. Respir Physiol. 1975;31:169-182.

62. Peters SP, Kunselman SJ, Icitovic N, et al. National heart, lung, and blood institute asthma clinical research network. Tiotropium step-up therapy for adults with uncontrolled asthma. $N$ Engl J Med. 2010;363:1715-1726.

63. Calverley PM, Lee A, Towse L, van Noord J, Witek TJ, Kelsen S. Effect of tiotropium bromide on circadian variation in airflow limitation in chronic obstructive pulmonary disease. Thorax. 2003;58:855-860.

64. Ceresa F, Angeli G, Buccuzzi G, Molino G. Once-a-day neutrally stimulated and basal ACTH secretion phases in man and their response to corticoid inhibition. J Clin Endocrinol. 1969;29:1074-1082.

65. Beam WR, Weiner DE, Martin RJ. Timing of prednisolone and alteration of airways inflammation in nocturnal asthma. Am Rev Respir Dis. 1992;146:1524-1530

66. Reinberg A, Halberg F, Falliers C. Circadian timing of methylprednisolone effects in asthmatic boys. Chronobiologia. 1974;1:333-347.

67. Barnes PJ, Pedersen S, Busse WW. Efficacy and safety of inhaled corticosteroids. New developments. Am J Respir Crit Care Med. 1998; 157(3 pt 2):S1-S53.

68. O'Byrne PM, Pedersen S, Busse WW, et al. Effects of early intervention with inhaled budesonide on lung function in newly diagnosed asthma. Chest. 2006;129:1478-1485.

69. Barnes PJ. Effect of corticosteroids on airway hyperresponsiveness. Am Rev Respir Dis. 1990;40:S70-S76.

70. Barnes PJ. Inhales glucocorticoids for asthma. $N$ Engl J Med. 1995;332:868-875.

71. Pincus DJ, Szefler SJ, Ackerson LM, Martin RJ. Chronotherapy of asthma with inhaled steroids: the effect of dosage timing on drug efficacy. J Allergy Clin Immunol. 1995;95:1172-1178.

72. Pincus DJ, Humeston TR, Martin RJ. Further studies on the chronotherapy of asthma with inhaled steroids: the effect of dosage timing on drug efficacy. J Allergy Clin Immunol. 1997;100:771-774.

73. Nave R, Meyer W, Fuhst R, Zech K. Formation of fatty acid conjugates of ciclesonide active metabolite in the rat lung after 4-week inhalation of ciclesonide. Pulm Pharmacol Ther. 2006;18:390-396.

74. Postma DS, Sevette C, Martinat Y, Schlosser N, Aumann J, Kafe J. Treatment of asthma by the inhaled corticosteroid ciclesonide given either in the morning or evening. Eur Respir J. 2001;17: 1083-1088. 
75. Buhl R, Vinkler I, Maygar P, et al. Comparable efficacy of ciclesonide once daily versus fluticasone propionate twice daily in asthma. Pulm Pharmacol Ther. 2005;19:404-412.

76. Kidney JC, Dominguez M, Taylor PM, Rose M, Chung KF, Barnes PJ. Immunomodulation by theophylline iin asthma. Demonstration by withdrawing of therapy. Am J Respir Care Med. 1995; 151:1907-1914.

77. Sullivan P, Songul B, Jaffar Z, Page C, Jeffery P, Costello J. Antiinflammatory effects of low dose oral theophylline in atopic asthma. Lancet. 1994;343:1006-1008.

78. Darow P, Steinijans VW. Therapeutic advantage of unequal dosing of theophylline in patients with nocturnal asthma. Chronobiol Int. 1987;4:349-357.

79. D'Alonzo GE, Smolensky MH, Feldman S, et al. Twenty-four hour lung function in adult patients with asthma. Chronoptimized theophylline therapy once-daily dosing in the evening versus conventional twice-daily dosing. Am Rev Respir Dis. 1990;142:84-90.

80. Kemp JP. Recent advances in the management of asthma using leukotriene modifiers. Am J Respir Med. 2003;2:139-156.

81. Drazen JM, Israel E, O'Byrne PM. Treatment of asthma with drugs modifying the leukotrien pathway. $N$ Engl J Med. 1999;340: 197-206.

82. Noonan MJ, Chervinsky P, Brandon PM, et al. Montelukast, a potent leukotriene receptor antagonist, causes dose-related improvements in chronic asthma. Montelukast Asthma Study Group. Eur Respir J. 1998;11:1232-1239.

83. Altman LC, Munk Z, Seltzer J, et al. A placebo-controlled, doseranging study of montelukast, acysteinyl leukotriene-receptor antagonist. Montelukast Asthma Study Group. JAllergy Clin Immunol. 1998;102:50-56.

84. Uematsu T, Nakano M, Kosuge K, Kanamaru M, Nakashima M. The pharmacokinetics of the beta 2-adrenoceptor agonist, tulobuterol, given transdermally and by inhalation. Eur J Clin Pharmacol. 1993;44(4):361-364
85. Burioka N, Miyata M, Endo M, et al. Alteration of the circadian rhythm in peak expiratory flow of nocturnal asthma following nighttime transdermal beta2-adrenoceptor agonist tulobuterol chronotherapy. Chronobiol Int. 2005;22:383-390.

86. Tamura G, Ohta K. Adherence to treatment by patients with asthma or COPD: comparison between inhaled drugs and transdermal patch. Respir Med. 2007;101:1895-1902.

87. Hozawa S, Haruta Y, Terada M, Yamakido M. Effects of the addition of Beta2-agonist tulobuterol patches to inhaled corticosteroid in patients with asthma. Allergol Int. 2009;58:509-518.

88. Bogin RM, Ballard RD. Treatment of nocturnal asthma with pulsedrelease albuterol. Chest. 1992;102:362-366.

89. Storms WW, Nathan RA, Bodman SF, et al. The effect of repeat action albuterol sulphate (Proventil Repetabs) in nocturnal symptoms of asthma. J Asthma. 1992;29:209-216.

90. Pedersen BK, Laursen LC, Gnosspelius Y, Faurschou P, Weeke B. Bambuterol: effects of a new anti-asthmatic drug. Eur J Clin Pharmacol. $1985 ; 29: 425-427$

91. Moore-Gillon J. Volmax (salbutamol CR $8 \mathrm{mg}$ ) in the management of nocturnal asthma: a placebo-controlled study. Eur Respir J. 1988;1:306s. [Abstract].

92. Creemers JD. A multicenter comparative study of salbuterol controlled release (Volmax) and sustained-release theophylline (Theo-Dur) in the control of nocturnal asthma. Eur Respir J. 1988;1(Suppl 2):333s [Abstract].

93. Reinberg A, Guillet P, Gervais P, Ghata J, Vignaud D, Abulker C. Onemonth chronocorticotherapy (Dutimelan 8-15 mite): control of the asthma condition without adrenal suppression and circadian alteration. Chronobiologia. 1977;4:295-312.

94. Leslie S. The Contin delivery system: dosing considerations. J Allergy Clin Immunol. 1986;78:768-773.

95. Shukla D, Chakraborty S, Mishra B. In vitro and in vivo evaluation of multi-layered pastilles for chronotherapeutic management of nocturnal asthma. Expert Opin Drug Deliv. 2012;9:9-18.
ChronoPhysiology and Therapy

\section{Publish your work in this journal}

ChronoPhysiology and Therapy is an international, peer-reviewed open access journal focusing on research into the cyclic variations and rhythmicity in physiological processes in the body and the research and development and optimal timing of administration of therapeutic targets to achieve improved outcomes and quality of life for the patient. The

\section{Dovepress}

manuscript management system is completely online and includes a very quick and fair peer-review system. Visit http://www.dovepress.com/ testimonials.php to read real quotes from published authors. 